\title{
Prevalence of migraine and tension-type headache among adults in Jordan
}

\author{
Karem H. Alzoubi · Nizar Mhaidat · Sayer Al azzam • \\ Yousef Khader · Saad Salem · Hanin Issaifan · \\ Rania Haddadin
}

Received: 10 February 2009/Accepted: 7 April 2009/Published online: 23 April 2009

(C) Springer-Verlag 2009

\begin{abstract}
Here, we investigated the prevalence of headache among adults in Jordan. The study was conducted from January 2007 to November 2008. A sample of 4,836 participants were permitted to complete a self-conducted screening questionnaire. As much as $82.3 \%$ of participants complained from headache at least once per year. $36.1 \%$ were tension-type headache and 59\% of the participants had other family members who suffered from headache. Headaches affected everyday activities in $51.6 \%$ of the participants; $82.7 \%$ of participants did not seek medical attention for their headaches. Among those who used analgesics (75.6\%), acetaminophen was the most common (91.43\%). In conclusion, headache and overuse of analgesics were prevalent in a significant part of the society. Thus, there is a need to educate the public to ensure safe practices and to make the use and selling of analgesics more stringent.
\end{abstract}

Keywords Headache Prevalence - Analgesics . Self-medication $\cdot$ Jordan

\section{Introduction}

Headache is one of the most common complaints of neurologic patients [1-4]. It is a common discomfort making

K. H. Alzoubi $(\varangle) \cdot$ N. Mhaidat · S. A. azzam - S. Salem ·

H. Issaifan · R. Haddadin

Department of Clinical Pharmacy, Faculty of Pharmacy,

Jordan University of Science and Technology,

Irbid 22110, Jordan

e-mail: khalzoubi@just.edu.jo

Y. Khader

Faculty of Medicine, Jordan University of Science

and Technology, Irbid, Jordan to the top ten list of complaints in ambulatory medical care, but our understanding of the epidemiology of headache disorders is still incomplete. Most of the recurrent headache cases are due to benign chronic primary headache disorders, such as tension headache and migraine. Less frequently, headache could be due to other underlying conditions such as infections, cerebral hemorrhage and brain lesions $[5,6]$. The study of headache epidemiology can address a number of important questions such as variation in the occurrence and severity of headache in the population, and the relationship between headache and other medical disorders. In addition, these studies may provide clues to abortive treatments and preventive strategies for headache [7].

Little is known of the prevalence of headache and the associated analgesic use. It is well documented among adults that overuse of headache medication may contribute to the development of chronic headache [8-14]. Epidemiologic studies indicate that chronic headache ( $>15$ days per month) is common in the adult population with a $2-5 \%$ prevalence rate [15-21] and a prevalence of chronic headache associated with medication overuse of about $1 \%$ $[18,20,21]$.

In general, self-medicating for headache is highly prevalent and self-care is likely to increase in the era of healthcare reform [22, 23]. This trend toward self-care is also very popular in the Middle East [24]. Chronic and inappropriate use of over-the-counter drugs such as analgesics, particularly nonsteroidal anti-inflammatory drugs (NSAIDs), can lead to overuse syndromes and drug-induced headache $[25,26]$.

In the present study, we sought to estimate the association between analgesic use and headache among adults in a large sample of the Jordanian population in relation to age, gender and headache frequency. 


\section{Methods}

In this study, participants (age range 18-85) were approached at their work places, classes or homes. A snowball sampling technique was used in collecting our data. In this procedure, researchers asked every participant to nominate two other persons until the desired sample size was obtained.

The study was ethically approved by the Institutional Review Board (IRB) at Jordan University of Science and Technology and was carried out in accordance with the principles described in the Declaration of Helsinki, including all amendments and revisions. Participants' written informed consent was obtained.

The study was conducted in various regions of Jordan during the period from January 2007 to November 2008. The questionnaire was distributed, in person, by the researchers, and was completed in the presence of the researcher. Each participant was provided with a full explanation of the study and how to complete the questionnaire. Participants were informed that the researcher would be available for any required assistance during scoring of the questionnaire. For the small group of participants who were illiterate, the questionnaire was administered by the researcher in the form of an interview. Completed questionnaires were collected by the researchers and rechecked to ensure completion. Confidentiality was maintained as no names and addresses of participants were required. Data were aggregated into groups and only the authors and the investigator were allowed access to the collected data.

The questionnaire gathered information that included demographic data, frequency and type of headache, and its impact on everyday activities, analgesic use, consultation of a doctor or pharmacist on the use, increase or decrease in the frequency of headache after painkiller usage, increase or decrease in painkiller dose and family history of headache. Every person who was 18 years or older was allowed to complete the survey. The questionnaire is available on requisite (khalzoubi@just.edu.jo).

To establish test-retest reliability, 50 subjects were selected randomly; they answered the questionnaire twice with a 1-week interval. Test-retest data on each item were analyzed using interclass correlation. For each item, correlation coefficients ranged from 0.79 to 0.86 , suggesting that the questionnaire was reliable.

The data were coded using the Statistical Package for the Social Sciences, version 15.0 (SPSS Inc., Chicago, IL, USA) entry program. The data were summarized using frequency tables and means and standard deviation for continuous variables. Frequency and contingency tables were used for categorical data.

\section{Results}

To estimate the prevalence of headache among adults in Jordan, a sample of participants (4,836 participants; mean age $27 \pm 0.4$ years, and male: female ratio of 59:41) was allowed to complete a self-conducted screening questionnaire. As shown in Table 1, about half of the participants (49.2\%) were university students and $78.3 \%$ were Jordanian citizens. Moreover, $70.7 \%$ participants were single and $47.4 \%$ were smokers.

Of the 4,836 participants, $82.3 \%$ complained of headache at least once per year. For both the 18-29 and the

Table 1 The demographic data of the study sample

\begin{tabular}{|c|c|}
\hline Variable & $n(\%)$ \\
\hline \multicolumn{2}{|l|}{ Gender } \\
\hline Male & $2,870(59.4)$ \\
\hline Female & $1,966(40.6)$ \\
\hline \multicolumn{2}{|l|}{ Age } \\
\hline $18-29$ years & $3,572(73.95)$ \\
\hline $30-39$ years & $506(10.46)$ \\
\hline $40-49$ years & $402(8.32)$ \\
\hline$\geq 50$ years & $356(7.37)$ \\
\hline \multicolumn{2}{|l|}{ Education } \\
\hline Illiterate & $83(1.7)$ \\
\hline Elementary school & $65(1.3)$ \\
\hline Secondary school & $213(4.4)$ \\
\hline High school & $610(12.6)$ \\
\hline Diploma & $344(7.1)$ \\
\hline University student & $2,378(49.2)$ \\
\hline Bachelor & $901(18.6)$ \\
\hline Masters & $181(3.7)$ \\
\hline Ph.D. & $61(1.3)$ \\
\hline \multicolumn{2}{|l|}{ Nationality } \\
\hline Jordanian & $3,787(78.3)$ \\
\hline Arab (non-Jordanian) & $841(17.4)$ \\
\hline Foreign & $208(4.3)$ \\
\hline \multicolumn{2}{|l|}{ Marital Status } \\
\hline Single & $3,422(70.8)$ \\
\hline Married & $1,304(27.0)$ \\
\hline Divorced & $55(1.14)$ \\
\hline Other & $55(1.14)$ \\
\hline \multicolumn{2}{|l|}{ Monthly income ${ }^{a}$} \\
\hline Low $(<$ or $=400 \mathrm{JD})$ & $257(5.3)$ \\
\hline Medium ( $>400$ JD to $<$ or $=1,000 \mathrm{JD}$ ) & $3,831(79.2)$ \\
\hline High $(>1,000$ JD $)$ & $748(15.5)$ \\
\hline \multicolumn{2}{|l|}{ Smoking } \\
\hline Smoker & $2,294(47.4)$ \\
\hline Non-smoker & $2,542(52.6)$ \\
\hline
\end{tabular}

a $1 \mathrm{JD}$ is equivalent to about 1.4 US Dollars 
30-39-year-old groups, the yearly prevalence of headache was found to be the same $(82.8 \%)$, while it was 79.9 and $81.7 \%$ for the $40-49$ and older than 50 -year-old groups, respectively.

Among the participants, $17.2 \%$ had daily headache attacks, while $25.7 \%$ had fewer than daily to weekly headaches, $21.6 \%$ had headaches on fewer than weekly up to monthly basis, $17.8 \%$ complained of headaches on a fewer than monthly basis and $17.7 \%$ of all participants did not experience headache attacks. Moreover, $38.4 \%$ of the headache complainers did not know the exact type of headache they were experiencing, 36.9\% complained of tension type headache and only $7.7 \%$ were diagnosed with migraine headache; $51.6 \%$ of complainers thought that headache affected their daily activities. A large number of participants stated that one or more of their family members complained of headache as well (Table 2).

Of the migrainers, $37.7 \%(n=140)$ complained of daily headache, $35.6 \%(n=132)$ had fewer than daily up to weekly headaches, and $18.1(n=67)$ and $8.6 \%(n=32)$ complained of headaches on a fewer than weekly up to monthly basis, and on fewer than monthly basis, respectively. Additionally, about $75 \%(n=279)$ of migrainers thought that migraine adversely affected their daily activities. Concerning tension type headache, $20.3 \%(n=348)$ complained of daily headache, $34.7 \%(n=594)$ had fewer than daily up to weekly headaches, and $24.1 \%(n=413)$

Table 2 Frequency, type, and family history of headache

\begin{tabular}{lr}
\hline Variable & $n(\%)$ \\
\hline Headache frequency & $832(17.2)$ \\
Daily & $1,243(25.7)$ \\
Fewer than daily to weekly & $1,043(21.6)$ \\
Fewer than weekly to monthly & $860(17.8)$ \\
Fewer than monthly to 1 year & $858(17.7)$ \\
No headache & \\
Type of headache & $372(7.7)$ \\
Migraine & $1,749(36.1)$ \\
Tension & $1,857(38.4)$ \\
Unknown & $858(17.7)$ \\
No headache & \\
Headache affects daily activities (if any) & $2,051(51.6)$ \\
Yes & $1,927(48.4)$ \\
No & $327(6.8)$ \\
Other family members complaining from headaches & \\
Father & $545(11.3)$ \\
Mother & $552(11.4)$ \\
Brothers or sisters & $558(11.5)$ \\
Other relatives & $860(17.8)$ \\
More than one family member & $1,994(41.1)$ \\
None &
\end{tabular}

and 20.8 ( $n=356)$ complained of headaches on fewer than weekly up to monthly basis, and fewer than monthly basis, respectively. Moreover, about 53\% $(n=907)$ indicated that tension type headache affected their daily activities. The stratified prevalence for both migraine and tension type headache according to age group and gender are shown in Table 3.

Only $17.3 \%$ of participants sought medical care for their headaches. This represents $49.7 \%$ of migrainers and $15.5 \%$ of participants with tension-type headache. Participants who used analgesics on a daily basis accounted for $15.2 \%$. The percentage of participants using analgesics on a weekly basis was $24.5 \%$, less than monthly but more than weekly was $24.8 \%$, monthly usage was $22.5 \%$, and the percentage of participants who never use a analgesics was $14.6 \%$. Participants who used analgesics on the advice of a physician were $15.3 \%$, while those who used analgesics on a pharmacist advice compromised $13.6 \%$. Those who used analgesics based on the experience of a family member or others were 34.8 and $47.4 \%$, respectively (Table 4). In addition, $13.1 \%$ of participants complained of increased headache severity or frequency on medication use. Results also revealed that $22.0 \%$ of participants had increased their analgesic dose and $78.0 \%$ did not change their regimen. The most frequently used analgesic among participants was acetaminophen $(78.00 \%)$, and to a lesser extent ibuprofen (7.49\%) and aspirin $(5.58 \%)$ (Table 5).

\section{Discussion}

In this study, we report for the first time an overall 1-year period prevalence of headache among adults in Jordan. A sample $(4,836)$ of participants were requested to complete a self-conducted screening questionnaire. As much as $82.3 \%$ of participants reported that they complained of headache at least once per year. This is much higher than the average global prevalence of headache $(46 \%)$ [27, 28]. Similar percentages were obtained from two studies conducted in

Table 3 Stratified prevalence of migraine and tension-type headache according to age group and gender

\begin{tabular}{lcrlll}
\hline $\begin{array}{l}\text { Headache } \\
\text { type } \\
\text { Gender }\end{array}$ & \multicolumn{2}{l}{ Tension-type headache } & & Migraine & \\
\cline { 2 - 3 } \cline { 5 - 6 } & $\begin{array}{l}\text { Male } n \\
(\%)\end{array}$ & $\begin{array}{l}\text { Female } n \\
(\%)\end{array}$ & & $\begin{array}{l}\text { Male } n \\
(\%)\end{array}$ & $\begin{array}{l}\text { Female } n \\
(\%)\end{array}$ \\
\hline Age category & (years) & & & \\
$18-29$ & $652(31.6)$ & $586(39.0)$ & & $158(7.7)$ & $97(6.5)$ \\
$30-39$ & $120(36.1)$ & $73(43.7)$ & & $34(10.2)$ & $11(6.7)$ \\
$40-49$ & $72(31.7)$ & $68(39.1)$ & & $17(7.5)$ & $18(10.3)$ \\
50 and above & $92(37.3)$ & $49(40.8)$ & $28(11.3)$ & $8(6.7)$ \\
Total & $936(32.6)$ & $776(39.5)$ & $237(8.3)$ & $134(6.8)$ \\
\hline
\end{tabular}


Table 4 Approach to medication use among patients with headache

\begin{tabular}{lr}
\hline Variable & $n(\%)$ \\
\hline Seeking medical help for headaches & $688(17.3)$ \\
Yes & $3,290(82.7)$ \\
No & \\
Advice on using analgesics ${ }^{\mathrm{a}}$ & $609(15.3)$ \\
Physician & $541(13.6)$ \\
Pharmacist & $1,383(34.8)$ \\
Family & $1,887(36.3)$ \\
Others (friends, co-workers, neighbors, etc.) & \\
Frequency of analgesics usage & $606(15.2)$ \\
Daily & $974(24.5)$ \\
Fewer than daily to weekly & $985(24.8)$ \\
Fewer than weekly to monthly & $829(22.4)$ \\
Fewer than monthly to 1 year & $584(14.6)$ \\
No analgesics & \\
Increase in headache frequency after analgesic use & $520(13.1)$ \\
Yes & $3,458(86.9)$ \\
No & \\
Increase analgesic dose used over time & $877(22.0)$ \\
Yes & $3,101(78.0)$ \\
No & \\
\hline a Some participants have sought the advice of more than one category
\end{tabular}

Table 5 Frequency of analgesics use among headache patients

\begin{tabular}{lc}
\hline Name of the analgesic used & $n(\%)$ \\
\hline Acetaminophen & $3,103(78.0)$ \\
Ibuprofen & $298(7.5)$ \\
Aspirin & $222(5.6)$ \\
Diclofenac sodium & $64(1.6)$ \\
Naproxen & $25(0.6)$ \\
Metamizole & $11(0.3)$ \\
Mefenamic acid & $10(0.3)$ \\
Ergotamine & $10(0.3)$ \\
Others & $137(3.5)$ \\
\hline
\end{tabular}

Note that some patients used more than one medication

other Middle Eastern countries namely Oman [29] and Qatar [30], and from other developing [31] and developed countries [32-34]. On the other hand, one study conducted in Oman showed a prevalence of headache of about $45 \%$ [35], however, that study was among university medical students and not the general population. In nearby Saudi Arabia, the prevalence of primary headaches ranged from 8 to $13 \%[30,36,37]$, which is much lower than that reported in all other studies from the Middle East area. The higher prevalence of headache in Jordan indicates that it is one of the major health problem.
Tension-type headache was found to be the most prevalent among other types of headaches (36.9\% compared to $7.7 \%$ for migraine). The prevalence of tension-type headache, in this study, falls within the prevalence range previously reported from studies conducted in the Middle East area $(11-39 \%)[29,35,38,39]$. Additionally, the reported prevalence for tension-type headache, in this study, is lower than its global prevalence (about 42\%) [27], which seems to be the case for the whole Middle East area. Studies on migraine headache from other Arab countries reported prevalence that ranged from 10 to $12.2 \%$ [29, 39, 40], which is higher than the migraine prevalence in our studied sample. As in the case of tension type headache, both the global migraine prevalence (about 11\%) [27], and the migraine prevalence in western Europe (about 14\%) [28] is higher than that in Jordan. Therefore, Jordan seems to have lower migraine prevalence than many other parts of the world. A recent study from nearby Qatar reported a migraine prevalence of about $8.0 \%$ [30], which is very similar to the prevalence reported in the current study.

Positive family history of headaches was found in most of our participants. The effect of headache on everyday activities was obvious in our study where a significant percentage $(51.6 \%)$ of participants ascertained that headache adversely affected their daily activities. Our results showed that $82.7 \%$ of participants did not seek medical attention for their headaches. In agreement with other's findings [29, 39], $75.6 \%$ of our population used analgesics and acetaminophen was the most popular $(78.0 \%)$. The popularity of acetaminophen over other analgesics could be related to its availability as an over-the-counter medication, low price, and because it is known to be safe to the gastrointestinal tract.

About $47 \%$ of the participants in our study were smokers. Previous studies from Jordan and surrounding countries reported smoking prevalence of about 26-48\%, depending on the gender, age and the specific population group studied [41-44]. Worldwide, the overall prevalence of smoking among adult males and females was estimated to ranges from 21 to $37 \%$ in the high-income countries, and 8.9 to $49 \%$ in low to middle income countries [45]. Therefore, the percentage of smokers obtained in this study is comparable to previous studies from the region and to low to middle income countries all over the world.

According to data obtained form the Jordanian Department of Statistics, about 38\% of Jordanian adult population falls into the age range of 19-29 year, which is considered a high percentage of young adults. In this study, however, $74 \%$ of the studied sample falls within the range of 18 29 years, and $47 \%$ of them were college students. Therefore, the studied sample appears to be not population based, which is one limitation of the current study. Another limitation is the fact that the sensitivity and specificity of the questionnaire was not tested. 
In summary, headache is a major health problem in Jordan, where $82.3 \%$ of participants experienced troublesome headache attacks at least once per year. Young adults were the most affected especially by tension-type headache. Analgesic overuse without seeking medical advice is regarded as potential for development of chronic headache. These results indicate the need for public education to ensure safe practices and to make the use and selling of analgesics more stringent.

Acknowledgments We would like to thank Ilham Swaidan PharmD, Alia Alasfar PharmD and Rana Aljaber PharmD for their help in data entry.

Conflict of interest None.

\section{References}

1. Ziegler DK (1990) Headache. Public health problem. Neurol Clin 8:781-791

2. Stewart AL, Greenfield S, Hays RD, Wells K, Rogers WH, Berry SD et al (1989) Functional status and well-being of patients with chronic conditions. Results from the medical outcomes study. JAMA 262:907-913

3. Osterhaus JT, Townsend RJ, Gandek B, Ware JE Jr (1994) Measuring the functional status and well-being of patients with migraine headache. Headache 34:337-343

4. Rasmussen BK (1995) Epidemiology of headache. Cephalalgia $15: 45-68$

5. Silberstein SD, Lipton RB, Dalessio DJ (2001) Overview, diagnosis, and classification of headache. In: Silberstein SD, Lipton RB, Dalessio DJ (eds) Wolff's headache and other head pain, 7th edn. Oxford university press, New York, pp 6-26

6. Deborah SK and Katherine CH (2005) Headache disorders, in pharmacotherapy: a pathophysiologic approach. In: Dipiro JP, Talbert RL, Yee JC, Matzke JR, Wells PG, Posey LM (eds) McGraw Hill, pp 1105-1121

7. Lipton RB, Silberstein SD, Stewart WF (1994) An update on the epidemiology of migraine. Headache 34:319-328

8. Lipton RB, Bigal ME (2003) Chronic daily headache: Is analgesic overuse a cause or a consequence? Neurology 61:154-155

9. Limmroth V, Katsarava Z, Fritsche G, Przywara S, Diener HC (2002) Features of medication overuse headache following overuse of different acute headache drugs. Neurology 59:1011-1014

10. Kudrow L (1982) Paradoxical effects of frequent analgesic use. Adv Neurol 33:335-341

11. Katsarava Z, Diener HC, Limmroth V (2001) Medication overuse headache: a focus on analgesics, ergot alkaloids and triptans. Drug Saf 24:921-927

12. Mathew NT, Stubits E, Nigam MP (1982) Transformation of episodic migraine into daily headache: analysis of factors. Headache 22:66-68

13. Rapoport AM (1988) Analgesic rebound headache. Headache 28:662-665

14. Solomon S, Lipton RB, Newman LC (1992) Clinical features of chronic daily headache. Headache 32:325-329

15. Castillo J, Munoz P, Guitera V, Pascual J (1999) Kaplan award 1998. Epidemiology of chronic daily headache in the general population. Headache 39:190-196

16. Hagen K, Zwart JA, Vatten L, Stovner LJ, Bovim G (2000) Prevalence of migraine and non-migrainous headache-head-hunt, a large population-based study. Cephalalgia 20:900-906
17. Lanteri-Minet M, Auray JP, El Hasnaoui A, Dartigues JF, Duru G, Henry P et al (2003) Prevalence and description of chronic daily headache in the general population in France. Pain 102:143-149

18. Lu SR, Fuh JL, Chen WT, Juang KD, Wang SJ (2001) Chronic daily headache in Taipei, Taiwan: prevalence, follow-up and outcome predictors. Cephalalgia 21:980-986

19. Scher AI, Stewart WF, Liberman J, Lipton RB (1998) Prevalence of frequent headache in a population sample. Headache 38: 497-506

20. Wang SJ, Fuh JL, Lu SR, Liu CY, Hsu LC, Wang PN et al (2000) Chronic daily headache in Chinese elderly: prevalence, risk factors, and biannual follow-up. Neurology 54:314-319

21. Zwart JA, Dyb G, Hagen K, Svebak S, Stovner LJ, Holmen J (2004) Analgesic overuse among subjects with headache, neck, and low-back pain. Neurology 62:1540-1544

22. Oates LN, Scholz MJ, Hoffert MJ (1993) Polypharmacy in a headache centre population. Headache 33:436-438

23. Sheftell FD (1997) Role and impact of over-the-counter medications in the management of headache. Neurol Clin 15:187-198

24. Dawson KP, Mcllvenny S, Quinn S, Harron DW (1996) Paracetamol prescribing - an epidemic? Fam Pract 13:179-181

25. Deleu D, Hanssens Y, Worthing EA (1998) Symptomatic and prophylactic treatment of migraine: a critical reappraisal. Clin Neuropharmacol 21:267-279

26. Elkind AH (1991) Drug abuse and headache. Med Clin North Am 75:717-732

27. Stovner L, Hagen K, Jensen R, Katsarava Z, Lipton R, Scher A et al (2007) The global burden of headache: a documentation of headache prevalence and disability worldwide. Cephalalgia 27:193-210

28. Stovner LJ, Hagen K (2006) Prevalence, burden, and cost of headache disorders. Curr Opin Neurol 19:281-285

29. Deleu D, Khan MA, Al Shehab TA (2002) Prevalence and clinical characteristics of headache in a rural community in Oman. Headache 42:963-973

30. Bener A (2006) Frequency of headache and migraine in Qatar. Neuroepidemiology 27:61-66

31. Ho KH, Ong BK (2001) Headache characteristics and race in Singapore: results of a randomized national survey. Headache 41:279-284

32. Nikiforow R (1981) Headache in a random sample of 200 persons: a clinical study of a population in northern Finland. Cephalalgia 1:99-107

33. Rasmussen BK, Jensen R, Schroll M, Olesen J (1991) Epidemiology of headache in a general population-a prevalence study. J Clin Epidemiol 44:1147-1157

34. Zwart JA, Dyb G, Holmen TL, Stovner LJ, Sand T (2004) The prevalence of migraine and tension-type headaches among adolescents in Norway. The Nord-Trondelag Health Study (headhunt-youth), a large population-based epidemiological study. Cephalalgia 24:373-379

35. Deleu D, Hanssens Y (1999) Primary chronic daily headache: clinical and pharmacological aspects. A clinic-based study in Oman. Headache 39:432-436

36. al-Rajeh S, Bademosi O, Ismaii H, Awada A (1990) Headache syndromes in the eastern province of Saudi Arabia. Headache 30:359-362

37. Abduljabbar M, Ogunniyi A, al Balla S, Alballaa S, al-Dalaan A (1996) Prevalence of primary headache syndrome in adults in the Qassim region of Saudi Arabia. Headache 36:385-388

38. Abdul Jabbar M, Ogunniyi A (1997) Sociodemographic factors and primary headache syndromes in a Saudi community. Neuroepidemiology 16:48-52

39. Deleu D, Khan MA, Humaidan H, Al Mantheri Z, Al Hashami S (2001) Prevalence and clinical characteristics of headache in medical students in Oman. Headache 41:798-804 
40. Jamal ST, Sharma PN, Ramadan FA, Boshehri FS (2004) Headache and blood pressure in primary health care setting in Kuwait. Saudi Med J 25:1849-1854

41. Maziak W (2002) Smoking in Syria: profile of a developing Arab country. Int J Tuberc Lung Dis 6:183-191

42. Maziak W, Mzayek F, Devereaux AV (2001) The dynamics of cigarette smoking during military service in Syria. Int $\mathrm{J}$ Tuberc Lung Dis 5:292-296
43. Youssef RM, Abou-Khatwa SA, Fouad HM (2002) Prevalence of smoking and age of initiation in Alexandria, Egypt. East Mediterr Health J 8:626-637

44. Khader YS, Alsadi AA (2008) Smoking habits among university students in Jordan: prevalence and associated factors. East Mediterr Health J 14:897-904

45. Slama K (2008) Global perspective on tobacco control. Part I. The global state of the tobacco epidemic. Int J Tuberc Lung Dis 12:3-7 